\title{
Syrian pharmacovigilance system: a survey of pharmacists' knowledge, attitudes and practices
}

Anas Bahnassi ${ }^{1,2}$ and Fawaz Al-Harbi ${ }^{3}$

${ }^{1}$ College of Pharmacy, Taibah University, Medina, Saudi Arabia (Correspondence to: Anas Bahnassi: abahnassi@taibahu.edu.sa). ${ }^{2}$ College of Pharmacy, Al-Rasheed University, Damascus, Syrian Arab Republic. ${ }^{3} \mathrm{Al}-$ Ansar Hospital, Ministry of Health, Medina, Saudi Arabia.

\begin{abstract}
Background: The Syrian pharmacovigilance (PV) system consists of a PV unit responsible for all related activities at the national level. Pharmacists' participation in the system can play a major role in its efficiency. To date, little is known about the position or the contribution of Syrian pharmacists within the programme.
\end{abstract}

Aims: To describe Syrian pharmacists' knowledge, attitudes, practices and perceived barriers to reporting of adverse drug reactions (ADR), and to evaluate the sociodemographic effects within Damascus and rural Damascus.

Methods: We used a self-administered, cross-sectional, questionnaire-based survey conducted on a random sample of 656 registered pharmacists in 2 Syrian governorates.

Results: The response rate was 77\%. Fifty-five percent of pharmacists had an acceptable level of knowledge about PV. Only $10.8 \%$ stated that they had reported an ADR at least once during their years of practice. Although $29.6 \%$ claimed they had reported ADRs to the Ministry of Health, $83.1 \%$ admitted that they did not know where or how they could get the official reporting forms.

Conclusions: Pharmacists who participated in the survey demonstrated limited knowledge towards PV and the Syrian PV system, and had relatively mixed attitudes towards reporting. Although they acknowledged the importance of ADR reporting, the current level of participation is low. The reasons for under-reporting were uncertainty of the fate of the reports, how they would be addressed, the complexity of the forms and the modest publicity of the PV programme.

Keywords: pharmacovigilance, adverse drug reactions, pharmacists, survey, Syria

Citation: Bahnassi A; Al-Harbi F. Syrian pharmacovigilance system: a survey of pharmacists' knowledge, attitudes and practices. East Mediterr Health J. 2018;24(6):569-578. https://doi.org/10.26719/2018.24.6.569

Received: 14/12/14; accepted: 09/05/17

Copyright (C) World Health Organization (WHO) 2018. Some rights reserved. This work is available under the CC BY-NC-SA 3.0 IGO license (https:// creativecommons.org/licenses/by-nc-sa/3.o/igo).

\section{Introduction}

Spontaneous reporting of adverse drug reactions (ADRs) of medicines is a crucial component of any national pharmacovigilance (PV) system and a vital tool required for improving and maintaining the appropriate use of medications (1). The World Health Organization (WHO) defines PV as "the science and activities related to the detection, assessment, understanding, and prevention of adverse reactions or any other drug-related problems" (2). An ADR is commonly defined as "a response to a medicinal product which is noxious and unintended and which occurs at doses normally used in man" $(2,3)$. The term "adverse drug reaction" needs to be distinguished from the term "adverse drug event" (ADE). Although other definitions exist (4-6) an $\mathrm{ADE}$ is defined as an adverse outcome that occurs while a patient is taking a drug, but is not or not necessarily attributable to it (3). Some ADEs are caused by errors classified as medication errors; these errors are usually more common than $\mathrm{ADEs}$, but only a small percentage cause ADEs (4).

Pharmacists play an important role in ensuring drug safety; they focus almost exclusively on drugs during their professional education (5). With the recent shift in pharmaceutical education toward a patient-centred focus, reporting $\mathrm{ADRs}$ is becoming one of the core duties of pharmacists. Sound clinical judgment of any medication error' $\mathrm{ADE}$ or $\mathrm{ADR}$; detailed information about the patient's past and current medical history; and insight into the effects of the drugs are required to make a correlation between the event and the drug involved $(5,6)$

In June 2012, the Syrian Arab Republic was admitted as an associate member of the WHO programme for international drug monitoring, and is currently awaiting full membership while compatibility between the national and international reporting formats is being established (7). The Syrian pharmacovigilance system (SPS) was established in 2011. It consists of a PV unit responsible for all related activities on the national level, and is linked to public hospitals, health programmes and local manufacturers, and internationally to the Uppsala Monitoring Centre (8). The PV unit has created an official online ADR reporting form, assigned PV officers in government hospitals, asked all working pharmaceutical companies in Syria to commission PV officers and initiated several training programmes $(8,9)$. Pharmacists' participation in the SPS can play a major role in the success of the programme. A survey to record the status of PV in 13 Middle Eastern countries concluded that the focus of policies was on detection and prevention of counterfeit 
medicines (10). The survey called for the exploitation of technology to enhance the ease of reporting of ADRs and related data management. Although officials from the Syrian Arab Republic were invited to participate, they did not respond, and the survey did not provide any data from this country. Surveys of 2 neighbouring countries, Jordan and Turkey, showed insufficient knowledge about the concept of PV and spontaneous reporting of ADRs $(11,12)$.

To date, little is known about the position or the contribution of Syrian pharmacists toward the instated SPS and ADRs reporting programme. Our objective was to describe Syrian pharmacists' knowledge, attitudes, practices and perceived barriers to ADR reporting and to evaluate the sociodemographic effect between the city and the countryside around Damascus.

\section{Methods}

\section{Study design}

This study was approved by the Institutional Research Committee, Taibah University, Saudi Arabia. It took place between December 2013 and July 2014. The study was a self-administered, cross-sectional, questionnaire-based survey conducted on a random sample of registered pharmacists in 2 Syrian governorates, the Syrian capital Damascus and the countryside around Damascus.

\section{Participants}

We identified our sample using a multi-step randomized (using a random number generator) and cluster (governorate) technique producing a sample of 857 pharmacists [city: 304 of a possible 1278 registered in the city (24\%); countryside: 553 of a possible 2140 registered in the countryside $(26 \%)$ ] with good-standing active licenses with the Syrian Syndicate of Pharmacists and practising in community or hospital settings. This method was used to divide the studied area (cluster) into smaller, more targeted clusters to create a more representative sample of the population that includes adequate representation of both governorates (clusters). The purpose of applying the cluster model is to examine the effect of sociodemographics in each governorate. In this case both clusters of this population were identified and pharmacists in these each of these clusters were surveyed (13).

\section{Survey instrument}

A comprehensive search was performed to retrieve appropriate articles/studies in PubMed, Ovid SP, Embassy, IPA, Ensco Medline, and Science Direct. The search approach engaged the keywords and/or the MeSH terms "pharmacovigilance", "adverse drug reactions," "pharmacists," and "reporting" combined with any alternative such as "adverse drug events," "Middle East," "Syria," "Arab countries," "knowledge" and "attitude." A self-administered questionnaire was designed after assessment of appropriate literature and surveys formerly utilized in analogous studies, which includes demographic information, respondent's comprehension in reference to PV concepts, the SPS, ADR reporting, their reporting practices, and the factors they perceive to be important as motivators or barriers to reporting $(9,10,12-16)$. A professional group of experts consisting of 3 administrative and social pharmacy professors, 1 clinical pharmacist and 1 psychologist critically studied, validated and approved the questionnaire for content. This survey was pilot tested on 12 pharmacists not participating in this study.

The semistructured questionnaire had a total of 19 items, divided into 5 main sections. The first section included 3 items, demographic, professional, and direct patient care involvement of the participating pharmacists.

The second section consisted of 5 questions to assess the knowledge of the respondents on some selected basic terminologies of PV. These questions included general definitions and specific differences among various PV concepts. Answers to these questions were graded with a score of 1 for each correct answer and o for each incorrect answer, with a maximum possible score of 5; the average and the median scores were estimated. The third section consisted of 8 statements to assess pharmacists' knowledge of the current reporting system, their attitude, and their behaviour concerning the reporting of ADRs. The responses to the questions in this section were listed in a 3-point Likert scale ranging from agree to neutral to disagree. The fourth section included 2 items about respondents' perceived barriers and motivators to reporting ADRs. These questions were also listed in a 3-point Likert scale as described for section 3. The fifth and final section was a general open-ended question for the respondents to make suggestions to increase the level of pharmacists' participation in reporting ADRs. Questionnaires with $>80 \%$ of unresolved answers were not included in the study analysis.

\section{Data collection}

The investigators visited the pharmacists at their practice sites to invite them to participate in an anonymous survey delivered by hand. No additional assistance or explanation was provided by the team on answering the questions. The survey included consent to participate in the study on a separate front sheet. Time to complete the survey was determined by the respondents, as well as the business volume when the survey was handed to them. The interviewing team was instructed to ensure the completeness of all survey questions by the participating pharmacists.

\section{Data analysis}

The results were statistically analysed using SPSS (version 17). The Pearson Chi-squared test was used to calculate $P$-values for categorical variables; $<0.05$ was considered statistically significant. Descriptive analyses were used to describe the collected data. Qualitative analysis was used to categorize pharmacists' comments into categories. Agreement was reached on classification of statements into themes after negotiation among the investigators relating to interpretation of the comments and consistency. 


\section{Results}

\section{Demographics}

The 857 pharmacists visited by our team returned 656 (77\%) valid surveys (city: 217 , countryside: 439 ). The rest of the pharmacists declined to participate, kept the survey promising to fill it at a later time but lost it or failed to return it the next day, or returned incomplete surveys. The first section of the survey showed statistically significant differences between the 2 governorates in age, number of years experience and education level (Table 1). The majority of the respondents were female $(64.5 \%)$ and most practised in privately owned independent pharmacies $(96 \%)$. The time range spent on direct patient contact varied, with the largest number (41.5\%) acknowledging direct patient contact ranging between 5 and $10 \mathrm{~min}$ for each patient interaction. Pharmacists practising in the countryside governorate spent more time with direct contact per patient in comparison with their counterparts in the city $(P=0.026)$.

\section{Knowledge of selected basic pharmacovigilance concepts}

The survey contained a group of multiple choice questions to assess the pharmacists' knowledge regarding selected basic PV-related concepts (Table 2). A 60\% score was considered acceptable. Although most respondents $(72 \%)$ identified the term ADR correctly according to the WHO definition (2), only $12 \%$ could make the distinction among the concepts of medication errors, ADEs and ADRs. The

\begin{tabular}{|c|c|c|c|c|}
\hline \multirow[t]{2}{*}{ Parameter } & $\begin{array}{c}\text { City } \\
(n=217)\end{array}$ & $\begin{array}{l}\text { Countryside } \\
(n=439)\end{array}$ & $\begin{array}{c}\text { Total } \\
(n=656)\end{array}$ & \multirow[t]{2}{*}{ P-value a } \\
\hline & No. (\%) & No. (\%) & No. (\%) & \\
\hline \multicolumn{5}{|l|}{ Age (years) } \\
\hline $20-29$ & $24(11.1)$ & $158(35.9)$ & $182(27.7)$ & \multirow{5}{*}{0.013} \\
\hline $30-39$ & $38(17.5)$ & $83(19)$ & $121(18.4)$ & \\
\hline $40-49$ & $57(26.3)$ & $103(23.5)$ & $160(24.4)$ & \\
\hline $50-59$ & $62(28.6)$ & $56(12.7)$ & $118(18.1)$ & \\
\hline$\geq 60$ & $36(16.5)$ & $39(8.9)$ & $75(11.4)$ & \\
\hline \multicolumn{5}{|l|}{ Sex } \\
\hline Female & $137(63.1)$ & $286(65.1)$ & $423(64.5)$ & 0.736 \\
\hline \multicolumn{5}{|l|}{ Highest pharmacy degree } \\
\hline Bachelor & $149(68.7)$ & $313(71.3)$ & $462(70.4)$ & \multirow{4}{*}{0.042} \\
\hline Masters & $29(13.4)$ & $47(10.7)$ & $76(11.6)$ & \\
\hline PhD/Pharm D & $14(6.4)$ & $7(1.6)$ & $21(3.2)$ & \\
\hline Not reportedb & $25(11.5)$ & $72(16.4)$ & $97(14.8)$ & \\
\hline \multicolumn{5}{|l|}{ Professional } \\
\hline \multicolumn{5}{|l|}{ Practice setting } \\
\hline Community & $194(89.4)$ & $436(99.3)$ & $630(96)$ & \multirow[t]{3}{*}{0.033} \\
\hline Hospital (inpatient) & $11(5.1)$ & $2(0.46)$ & $13(2)$ & \\
\hline Hospital (outpatient) & $12(5.5)$ & $1(0.23)$ & $13(2)$ & \\
\hline \multicolumn{5}{|l|}{ Experience (years) } \\
\hline$<2 c$ & $\mathrm{o}(0)$ & $212(48.3)$ & $212(32.3)$ & \multirow{5}{*}{0.027} \\
\hline $2-5$ & $28(12.9)$ & $118(26.9)$ & $146(22.3)$ & \\
\hline $6-10$ & $67(30.9)$ & $57(13)$ & $124(18.9)$ & \\
\hline $11-15$ & $88(40.6)$ & $23(5.2)$ & 111 (16.9) & \\
\hline$>15$ & $34(15.6)$ & $29(6.6)$ & $63(9.6)$ & \\
\hline \multicolumn{5}{|c|}{$\begin{array}{l}\text { Average time spent in direct contact with patient for each prescription } \\
\text { (min) }\end{array}$} \\
\hline$<5$ & $126(58.1)$ & $92(21)$ & 218 (33.2) & \multirow{4}{*}{0.026} \\
\hline $5-9$ & $61(28.1)$ & $211(48.1)$ & $272(41.5)$ & \\
\hline $10-15$ & $26(12)$ & $81(18.5)$ & $107(16.3)$ & \\
\hline$>15$ & $4(1.8)$ & $55(12.4)$ & 59 (9) & \\
\hline
\end{tabular}

${ }^{a}$ Chi-squared test.

${ }^{b}$ Although unanswered, the minimum required for licensure in Syria is to obtain a bachelor degree.

'In Syria, pharmacists cannot practice in the city without a minimum 2 years experience in the countryside. 
term PV was correctly defined by less than $26 \%$ of the respondents. Pharmacists practising in the countryside provided more correct answers to the questions compared with their peers practising in the city $(P=0.003)$. The total number of pharmacists with an acceptable level of knowledge (score $3 / 5$ or more) was 361 (55\%). The total median score for the questions in this section was a poor score of 2 (interquartile range 2 ) out of a possible maximum score of 5. The average score was 2.06 (standard deviation 1.18). We did not run a test for normal distribution of the data.

\section{Knowledge of the Syrian pharmacovigilance system, attitude and practice}

A total of 504 pharmacists (city: 116; countryside: 388) did not know about the SPS provided by the Ministry of Health (Table 3). Those who were aware of the system said they had acquired this knowledge from other pharmacists $(57.8 \%)$ or through formal publications by the Ministry of Health (53.9\%). Only 71 pharmacists (10.8\%) (city: 25; countryside: 46) stated that they had reported an $\mathrm{ADR}$ at least once during their years of practice, not necessarily to the Ministry of Health. Although 21 of them $(29.6 \%)$ claimed that they reported these ADRs to Ministry of Health using the proper submission process, $59(83.1 \%)$ admitted that they did not know where or how they could get the official reporting forms.

There was no significant difference $(P>0.05)$ between the 2 governorates in terms of utilization of the reporting system (data not shown). Almost $40 \%$ of the respondents believed that reporting is a professional duty of all pharmacists. Most stated that it is a shared responsibility with the pharmaceutical industry (78.1\%) (Table 3). Approximately $18.3 \%$ suggested that the reporting process can help improve pharmacists' knowledge about available medications in the market. No significant differences in attitudes were observed among respondents in terms of age, sex, experience, governorate and practice setting $(P$ $>0.05)$.

\section{Perceived barriers and motivators}

Factors that encouraged pharmacists to utilize the reporting system were ranked by the participating pharmacists (Table 4). The factors with the most "agree" responses were ranked top. These factors were similar in both groups of participating pharmacists. The level of seriousness of the ADR to the patient (death, life-threatening, hospitalization, disability, function, or organ impairment, congenital anomaly) topped the motivating factors for pharmacists to report ADRs (49.7\%) followed by the severity of the ADR reported (47.6\%), and the fact that the $\mathrm{ADR}$ being reported is for a newly available drug (32.9\%). A newer ADR of an existing drug and the frequency of the ADR were among the factors ranked top by fewer respondents, at $27.6 \%$ and $10.4 \%$, respectively. Several barriers to reporting were reported (Table 5). Poor availability of forms was perceived as a top barrier by $70.2 \%$ of the pharmacists who provided valid responses, $54.3 \%$ did not report because they do not have the time, $44.4 \%$ did not report because they do not know how to report ADRs, and $38.1 \%$ found the reporting system too complex. About 31\% of our respondents feared that the ADR might be wrongfully reported. Legal accountability, complacency and lack of clinical training were ranked the least important factors by our pharmacists.

\section{Pharmacists' comments on the level of participation in the Syrian pharmacovigilance system}

The survey contained 1 open-ended question, in which the pharmacists were asked to provide comments on the PV system in the country. Comments were provided by only 41 pharmacists (city 13; countryside 28 ) and were categorized under 3 major themes.

- Disappointment with the system $[n=19$ (city 4; countryside 15)] including statements such as:

- "Reporting will not result in effective follow-up from the responsible authorities."

- " Reporting is a waste of time and effort."

- "Reports will not reach listening ears."

- Reports of a complicated reporting process ( $n=13$; city 7; countryside 6) with statements such as:

- " "It is too complicated."

- "We were not trained to do it."

- "I feel like I am taking an exam when I fill this form."

- Poor engagement of pharmacists in the patient's therapeutic plan ( $n=9$; city 2 ; countryside 7 ) with statements such as:

- "Patients usually report these to their physicians."

- "We cannot be sure of the relationship of the reaction to the drug because we do not know the full history of the patient."

- "We do not have the tools to know about patients' current and past medications."

\section{Discussion}

\section{Knowledge of the Syrian pharmacovigilance system and selected basic concepts}

Knowledge and attitude of pharmacists on ADR reporting could greatly influence their practice and thereby contribute to patient safety. The assessment of these parameters will help in identifying the interventions needed to be taken by different parties to ensure the success of the national PV programme. This is the first study of its kind in the Syrian Arab Republic that sought to assess the knowledge, attitude and practice of pharmacists concerning the national SPS.

Data reported from neighbouring countries indicate poor knowledge of PV concepts among pharmacists. In Jordan (11), only $25.5 \%$ defined PV correctly while $69.7 \%$ defined ADR correctly, and only $17.2 \%$ of the Turkish community pharmacists interviewed had 


\begin{tabular}{|c|c|c|c|c|c|c|}
\hline \multirow[t]{2}{*}{ Question } & \multicolumn{3}{|c|}{$\begin{array}{c}\text { Correct answer } \\
\text { No./total valid answers (\%) }\end{array}$} & \multicolumn{3}{|c|}{$\begin{array}{c}\text { Incorrect answer } \\
\text { No./total valid answers (\%) }\end{array}$} \\
\hline & City & Country & Total & City & Country & Total \\
\hline $\begin{array}{l}\text { What is an ADR? } \\
\text { Harmful effects which occur when a drug is used in the } \\
\text { usual dose. } \\
\text { Unexpected responses to a drug when it is used at a higher } \\
\text { dose. } \\
\text { Harmful effects which occur when the patient is taking a } \\
\text { drug but it is not necessarily related to the drug. } \\
\text { None of the above. }\end{array}$ & $\begin{array}{c}148 / 215 \\
(68.2)\end{array}$ & $\begin{array}{c}322 / 438 \\
(73.5)\end{array}$ & $\begin{array}{c}471 / 653 \\
(72.1)\end{array}$ & $67 / 215(31.2)$ & $\begin{array}{c}116 / 438 \\
(26.5)\end{array}$ & $\begin{array}{c}182 / 653 \\
(27.9)\end{array}$ \\
\hline $\begin{array}{l}\text { Which statement regarding ADRs is correct? } \\
\text { ADRs are always preventable. } \\
\text { ADRs are preventable to some extent. } \\
\text { ADRs are not preventable at all. } \\
\text { ADRs refer only to the serious harmful effects of drugs. }\end{array}$ & $152 / 217(70)$ & $\begin{array}{c}371 / 439 \\
(84.5)\end{array}$ & $\begin{array}{c}523 / 656 \\
(79.7)\end{array}$ & $65 / 217(30)$ & $68 / 419$ (15.5) & $\begin{array}{c}133 / 656 \\
(20.3)\end{array}$ \\
\hline $\begin{array}{l}\text { What is pharmacovigilance? } \\
\text { The skills required by each practising pharmacist to provide } \\
\text { a patient-centred pharmaceutical care. } \\
\text { The science and activities related to the detection, } \\
\text { assessment, understanding, and prevention of adverse } \\
\text { reactions or any other drug-related problems. } \\
\text { The monitoring activities conducted by the government to } \\
\text { assure the availability and accessibility of pharmaceutical } \\
\text { preparations. } \\
\text { The scientific discipline that identifies, measures, and } \\
\text { compares the costs and consequences of drug therapy to } \\
\text { healthcare systems and society. }\end{array}$ & $14 / 212(6.6)$ & $\begin{array}{l}159 / 431 \\
(36.9)\end{array}$ & $\begin{array}{c}173 / 643 \\
(26.9)\end{array}$ & $\begin{array}{c}198 / 212 \\
(93.4)\end{array}$ & $\begin{array}{c}280 / 431 \\
(63.8)\end{array}$ & $\begin{array}{c}470 / 643 \\
(73.1)\end{array}$ \\
\hline $\begin{array}{l}\text { The difference between } \mathrm{ADR} \text { and } \mathrm{ADE} \text { is: } \\
\text { An } \mathrm{ADE} \text { is a special type of } \mathrm{ADR} \text { in which a causative } \\
\text { relationship between the drug and the reaction can be } \\
\text { shown. } \\
\text { An } \mathrm{ADE} \text { is an adverse outcome that occurs while a patient is } \\
\text { taking a drug, but is not necessarily attributable to it, while } \\
\text { the } \mathrm{ADR} \text { is a necessarily attributed to the drug provided. } \\
\text { An } \mathrm{ADE} \text { is an expected outcome that occurs while the } \\
\text { patient is taking a drug, while the } \mathrm{ADR} \text { is always an } \\
\text { unexpected outcome of the drugs. } \\
\text { There is no difference between the terms. }\end{array}$ & $19 / 215(8.8)$ & $\begin{array}{c}54 / 434 \\
(12.4)\end{array}$ & $73 / 649$ (11.2) & $\begin{array}{c}196 / 215 \\
(91.2)\end{array}$ & $\begin{array}{c}380 / 434 \\
(87.6)\end{array}$ & $\begin{array}{c}576 / 649 \\
(88.8)\end{array}$ \\
\hline $\begin{array}{l}\text { How is medication errors related to adverse drug reactions } \\
\text { and adverse drug events? } \\
\text { Not related. } \\
\text { ADRs can be caused by medication errors. } \\
\text { ADEs can be caused by medication errors. } \\
\text { Both ADRs and ADEs can be caused by medication errors. }\end{array}$ & $18 / 215(8.4)$ & $58 / 434(13.4)$ & $76 / 649$ (11.7) & $\begin{array}{c}197 / 215 \\
(91.6)\end{array}$ & $\begin{array}{c}376 / 434 \\
(86.6)\end{array}$ & $\begin{array}{c}573 / 649 \\
(88.3)\end{array}$ \\
\hline
\end{tabular}

$\mathrm{ADR}=$ adverse drug reaction.

any knowledge about PV (12). Another study found pharmacists' knowledge in regard to drug safety in the Palestinian territories to be very limited (17). Our results found Syrian pharmacists' knowledge to be comparable to their peers in the region $(11,12,16)$. Most pharmacists still lack the ability to identify the PV concept, or to differentiate between the terms associated with it; this knowledge gap may limit their ability to identify ADEs or ADRs for reporting purposes (14). At the same time, the poor level of knowledge observed can negatively impact the accuracy and the validity of the whole reporting system. We believe that the low reporting rate in our sample may be related to the retail setting environment in Syrian pharmacies, where minimum interaction takes place between pharmacist and patient, unfamiliarity with the terms, the ambiguity of the reporting process and requirements, and the limited access to reporting forms, as suggested in previous studies $(11,12,17,18)$. Although pharmacists practising in the countryside were significantly younger, with less experience in terms of years, a significantly higher number of them expressed adequate knowledge of SPS. Those with a Master's degree were more familiar with the concept of PV. There was no significant difference between the 2 groups on the level of utilization of the reporting system. A poor overall knowledge on the Ministry of Health reporting system for ADRs was observed (23.2\%). This is a serious indicator of the ineffectiveness of the activities set up by 


\begin{tabular}{|c|c|c|c|}
\hline \multirow[t]{2}{*}{ Statement } & \multicolumn{3}{|c|}{ Level of agreement, No. (\%) } \\
\hline & Agree & Neutral & Disagree \\
\hline $\begin{array}{l}\text { I am familiar with the Syrian pharmacovigilance system (SPS) administered by the Ministry } \\
\text { of Health }\end{array}$ & $\begin{array}{c}128 \\
(19.5)\end{array}$ & $\begin{array}{c}24 \\
(3.7)\end{array}$ & $\begin{array}{c}504 \\
(76.8)\end{array}$ \\
\hline \multicolumn{4}{|l|}{ Ilearned about SPS through: ${ }^{a}$} \\
\hline Professional meeting & $14(10.9)$ & $11(8.6)$ & $103(80.5)$ \\
\hline Official ministry publication & $69(53.9)$ & $7(5.5)$ & $52(40.6)$ \\
\hline A continuing education session & $2(1.6)$ & $4(3.1)$ & $122(95.3)$ \\
\hline Pharmaceutical company publication & $6(4.6)$ & $37(28.9)$ & $85(66.5)$ \\
\hline Other pharmacists & $74(57.8)$ & $8(6.3)$ & $46(35.9)$ \\
\hline $\begin{array}{l}\text { I know about the online form to report adverse drug reactions available from the Ministry } \\
\text { of Health website }\end{array}$ & $107(16.3)$ & $27(4.1)$ & $522(79.6)$ \\
\hline $\begin{array}{l}\text { I have used the online form to report and adverse drug reaction at least once during my } \\
\text { practice }\end{array}$ & $71(10.8)$ & $22(3.4)$ & $563(85.8)$ \\
\hline \multicolumn{4}{|l|}{ I have used the online form to report an adverse drug reaction to: ${ }^{b}$} \\
\hline The Ministry of Health & $21(29.6)$ & $0(0)$ & $50(70.4)$ \\
\hline Pharmaceutical company over the phone & $6(8.5)$ & $2(2.8)$ & $63(88.7)$ \\
\hline A company representative in person & $26(36.6)$ & $0(0.0)$ & $45(63.4)$ \\
\hline The company distributor & $2(2.8)$ & $12(16.9)$ & $57(80.3)$ \\
\hline Reporting adverse drug reactions is pharmacist's professional duty & $247(37.6)$ & $127(19.3)$ & $282(42.9)$ \\
\hline \multicolumn{4}{|l|}{ Besides pharmacists, reporting adverse drug reactions is the responsibility of: } \\
\hline Prescriber & $141(21.5)$ & $442(67.4)$ & $73(11.1)$ \\
\hline Patient & $87(13.3)$ & $372(56.7)$ & $197(30)$ \\
\hline Allied health professional & $51(7.7)$ & $106(16.2)$ & $499(76.1)$ \\
\hline Drug company & $512(78.1)$ & $82(12.5)$ & $62(9.4)$ \\
\hline \multicolumn{4}{|l|}{ The primary goal of adverse drug reactions reporting is (Please pick only one): } \\
\hline Patient safety & & $449(68)$ & \\
\hline Transparency of exchanging clinical knowledge among healthcare practitioners & & $73(11)$ & \\
\hline Comprehensive understanding of the drug actions & & $95(15)$ & \\
\hline Improving patient's adherence to medication & & $33(5)$ & \\
\hline Other & & $6(1)$ & \\
\hline
\end{tabular}

${ }^{a}$ Numbers and percentages are calculated out of the 128 participants who stated they were familiar with the pharmacovigilance system. Percentages may add up to more than 100 since some pharmacists claimed they reported to more than one entity.

${ }^{b}$ Numbers and percentages are calculated out of the 71 participants who stated they had used the online form. Percentages may add to more than 100 since some pharmacists claimed they reported to more than one entity.

the Ministry of Health in raising awareness about the programme. Nevertheless, it is better than the findings from some studies in Turkey (17.2\%) and Saudi Arabia $(13.2 \%)(12,18)$ and comparable to results from a Jordanian study $(26 \%)(11)$.

\section{Attitude and practice}

Our results demonstrated mixed attitudes among pharmacists towards reporting. It was encouraging to note that respondents mostly demonstrated a good understanding of the purpose of reporting and a fair proportion (38\%) considered reporting of ADRs to be a professional responsibility. This is still much lower than results reported from neighbouring countries, where $97 \%$ of the pharmacists interviewed in a Saudi Arabian study considered the reporting of ADRs to be an integral part of pharmaceutical care, and in Turkey, where $89 \%$ of the pharmacists believed that the role of the pharmacist in the reporting of ADRs was essential $(12,18)$.

However, lower reporting rates were seen in some neighbouring countries. Only $4 \%$ of the pharmacists surveyed in a Saudi Arabian study claimed that they had submitted an ADR report to the Ministry of Health and $6.3 \%$ claimed that they had submitted a report to the pharmaceutical company (18). Less than $20 \%$ of the pharmacists in Jordan reported at least one ADR during the years of their practice (11). In Turkey, $65 \%$ of the pharmacists surveyed stated that patients reported an ADR to them during the previous 12 months, however, only $21 \%$ reported these ADRs to the organizations concerned (12).

Attitudes are modifiable factors (11,14,16), and structured continuing education programmes and adequate promotion programmes can help improve the 


\begin{tabular}{|c|c|c|c|c|}
\hline \multirow[t]{2}{*}{ Factor } & \multicolumn{3}{|c|}{ Ranking (\%) } & \multirow[t]{2}{*}{ Not ranked } \\
\hline & Top & Middle & Least & \\
\hline Incidence of the ADR & 10.4 & 45.9 & 36.3 & $7 \cdot 5$ \\
\hline New ADR of an older drug & 27.6 & 49.9 & 13.3 & 9.3 \\
\hline Severity of the reactiona & 47.6 & 23.2 & 14.9 & 14.3 \\
\hline Level of seriousness to the patient & 49.7 & 24.5 & 10.4 & 15.4 \\
\hline ADR of a newly available drug & 32.9 & 37.2 & 21.5 & 8.4 \\
\hline
\end{tabular}

$\mathrm{ADR}=$ adverse drug reaction.

low reporting rates seen among pharmacists in Syria. The majority of our respondents were community pharmacists (96.3\%); other studies have found hospital pharmacists to use the reporting system more frequently than community pharmacists (11).

\section{Perceived barriers and motivators}

We identified several factors that discourage pharmacists from reporting ADRs. In the city, time constraints were the number one barrier. Lack of knowledge on the reporting process and concern that these $\mathrm{ADRs}$ might be wrongfully reported were ranked highest in the countryside. Some of these factors were observed in other studies in the region. Similar to studies conducted among pharmacists in Jordan, Turkey and Saudi Arabia $(11,12,18)$, our pharmacists reported limited availability of forms as the principal barrier at around 70\%. Other barriers cited were lack of knowledge on how to report, time constraints and fear of wrongfully reporting an ADR. Contrary to other reports $(9,10,12,13,16)$, our pharmacists did not see a lack of clinical training, complacency or legal accountability as barriers to utilizing the reporting system.

As in Jordan (11), our respondents ranked the level of seriousness of the reaction as the top motivator,. A new ADR was ranked top by $27.6 \%$ of our respondents $(87.9 \%$ in Jordan), and if the ADR concerned a new drug, it was ranked top by $33 \%$ of our respondents ( $57 \%$ in Jordan). While the severity of the reaction was ranked top by $47.6 \%$ of our study respondents, the study in Jordan discussed the "unusual" nature of the reaction and this was perceived as a barrier by $97.6 \%$ of the pharmacists (11).

\section{Comments on the level of participation in the pharmacovigilance system}

Analysis of the pharmacists' comments showed uncertainty concerning the fate and the handling of the submitted reports, in particular they suspected the transparency with which their reports were addressed. It is obvious that the Ministry of Health needs to provide a clear explanation of the correct handling and processing of these reports. Although these points are listed on the programme website (10), PV awareness programmes and feedback pathways need to be established by the Ministry of Health and promoted more frequently among practising pharmacists in all settings. The submission process involved faxing or emailing the form; a direct online submission method with a receipt acknowledgement would provide a suitable solution to this problem. Comments also showed that pharmacists were disappointed with the complexity of the form itself and the submission process. We noted that the available form did not come with any guide or any explanation of the steps taken by the Ministry of Health following the reporting process. Although these steps were explained in Ministry of Health educational programmes, these programmes are limited and could not reach out to an adequate number of pharmacists. Finally, pharmacists felt that their level of engagement in the patient's therapeutic plan was minimal. This was shown to be a huge barrier for pharmacists to deliver clinical services, even in western countries (19). Pharmacists had difficulties identifying and dealing with different drug-related problems, including ADRs or ADEs,

\begin{tabular}{|c|c|c|c|c|}
\hline \multirow[t]{2}{*}{ Factor } & \multicolumn{3}{|c|}{ Ranking (\%) } & \multirow[t]{2}{*}{ Not ranked } \\
\hline & Top & Middle & Least & \\
\hline System complexity & 38.1 & 26.4 & 33.7 & 1.8 \\
\hline Availability of forms & 70.2 & 11.4 & 15.8 & 2.6 \\
\hline Complacency & 9.6 & 12.1 & 67.2 & 11.1 \\
\hline Legal accountability & 129 & 9.9 & 71.1 & 6.1 \\
\hline Lack of clinical training & 7.4 & 8.1 & 82.3 & 2.2 \\
\hline ADRs may be wrongfully reported & 31.2 & 21.5 & 42.1 & 5.2 \\
\hline Lack of knowledge of the process & 44.4 & 18.4 & 32.6 & 4.6 \\
\hline Time constraints & 54.3 & 22.3 & 21.3 & 2.1 \\
\hline
\end{tabular}

$\mathrm{ADR}=$ adverse drug reaction . 
because they did not have full access to the patient's past and current medical situation.

Our study did have some limitations. Most respondents did not have a reliable internet access in their practice and this limited their access to the online reporting system. This barrier was not discussed in our study. Most pharmacists interviewed practised in the community, which may have contributed to the modest levels of knowledge and utilization obtained. Many pharmacists left some of the questions unanswered, or provided the same rank in their answers to many of the questions, which may have lead to some bias in the answers to these questions. Additionally, the number of pharmacists who left comments was very low.

Furthermore, since the system is in the early stages of implementing the reporting of ADRs, many pharmacists may face different barriers trying to use the system for the first time in the future. Further research adopting a work environment approach to examining barriers and motivators in reporting ADRs is required.

\section{Lessons learnt}

Most pharmacists surveyed did not achieve the $60 \%$ acceptable score in the knowledge of PV terminology and ADR reporting. There is an urgent need for educational programmes to raise awareness regarding the national
PV system in the country, and to emphasize the role of pharmacists in ensuring drug safety and their responsibility to report ADRs. The role of pharmacists in the reporting of ADRs may differ from one jurisdiction to another, but their professional responsibility to report must always be an integral part of their professional duties.

\section{Conclusions}

Pharmacists who participated in the survey demonstrated limited knowledge towards PV and SPS, but relatively mixed attitudes towards reporting. Although they acknowledged the importance of ADR reporting, the current level of participation is low. The reasons for under-reporting were the uncertainty of the fate of the reports, the modality used to address these reports, the complexity of the forms and the modest publicity of the programme.

Finally, pharmacists felt they were not effectively engaged in the patient's therapeutic plan to identify the causal relation between the drug and the reaction. A future study covering all Syrian governorates would generate more-valuable data to support the findings of our study.

\section{Funding: None.}

Competing interests: None declared.

\section{Le système de pharmacovigilance syrien : étude des connaissances, des attitudes et des pratiques des pharmaciens \\ Résumé}

Contexte: Le système de pharmacovigilance syrien est constitué d'une unité de pharmacovigilance responsable de toutes les activités associées au niveau national. La participation des pharmaciens au système contribue de façon décisive à son efficacité. À ce jour, peu d'informations sont disponibles sur la position des pharmaciens syriens à l'égard de ce programme ou sur leur contribution.

Objectif : Décrire les connaissances, les attitudes, les pratiques et les facteurs de frein perçus des pharmaciens syriens en matière de déclaration des réactions indésirables aux médicaments, ainsi qu'évaluer les conséquences sociodémographiques observées dans Damas et Damas rural.

Méthodes : Une étude transversale reposant sur un questionnaire auto-administré a été conduite sur un échantillon aléatoire composé de 656 pharmaciens agréés dans deux gouvernorats syriens.

Résultats : Le taux de réponse était de $77 \%$. Cinquante-cinq pour cent des pharmaciens avaient un niveau de connaissance du système de pharmacovigilance acceptable. Seuls 10,8\% ont déclaré avoir rapporté un réaction indésirable au moins une fois au cours de leurs années d'exercice. Bien que 29,6\% aient affirmé avoir notifié des réactions indésirables aux médicaments auprès du ministère de la Santé, 83,1 \% ont admis qu'ils ignoraient où et comment se procurer les formulaires de déclaration officiels.

Conclusion : Les pharmaciens ayant participé à l'étude avaient une connaissance limitée de la pharmacovigilance et du système de pharmacovigilance syrien, et avaient des attitudes relativement mitigées vis-à-vis de la déclaration. Bien qu'ils aient reconnu l'importance de la déclaration des réactions indésirables aux médicaments, le niveau de participation actuel reste faible. Les raisons de la sous-déclaration étaient le fait de ne pas savoir ce qu'il adviendrait de ces déclarations, la façon dont celles-ci seraient traitées, la complexité des formulaires et la faible publicité autour du programme de pharmacovigilance. 


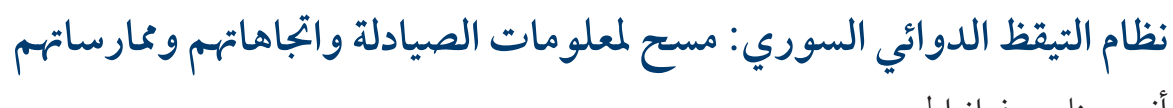

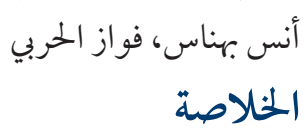

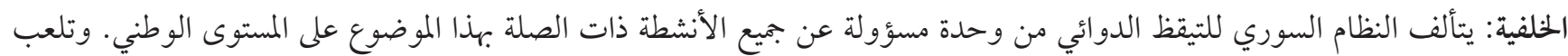

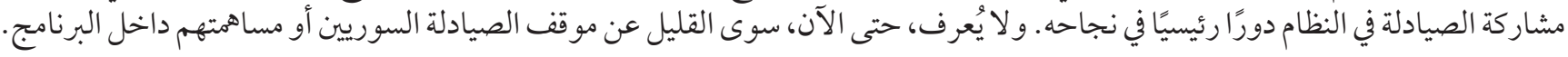

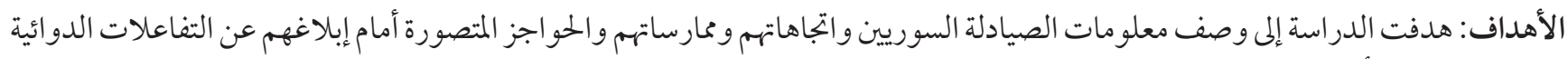
الضارة، وتقييم الأثر الاجتماعي السكاني بين المدينة والريف المداليف المحيط بدمشق.

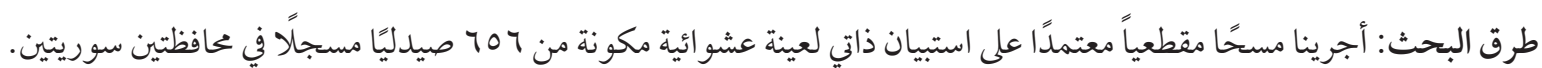

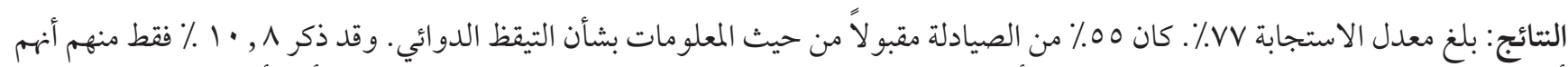

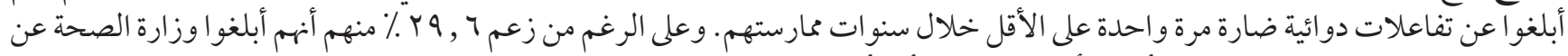

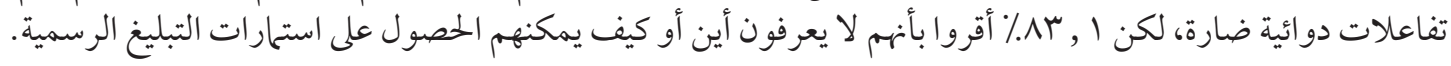

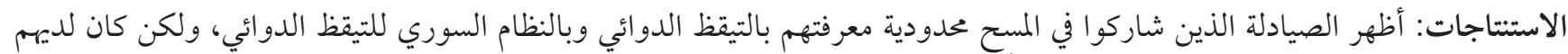

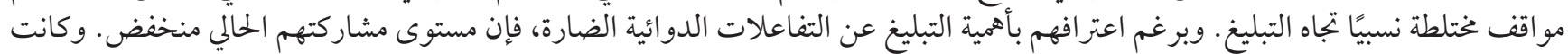

\section{References}

1. WHO patient safety research: better knowledge for safer care. Geneva: World Health Organization; 2009 (http://whqlibdoc.who. int/hq/2009/WHO_IER_PSP_2009.10_eng.pdf, accessed 3 March 2018).

2. The importance of pharmacovigilance - safety monitoring of medicinal products. Geneva. World Health Organization; 2002 (http://apps.who.int/medicinedocs/en/d/Js4893e/, accessed 3 March 2018).

3. Edwards IR, Aronson JK. Adverse drug reactions: definitions, diagnosis, and management. Lancet. 2000;356(9237):1255-9. PMID:11072960

4. Bates DW, Cullen DJ, Laird N, Petersen LA, Small SD, Servi D, et al. Incidence of adverse drug events and potential adverse drug events: Implications for prevention. ADE prevention study group. JAMA. 1995;274:29-34. PMID:7791255

5. van Grootheest K, Olsson S, Couper M, de Jong-van den Berg L. Pharmacists' role in reporting adverse drug reactions in an international perspective. Pharmacoepidemiol Drug Saf. 2004;13(7), 457-64. PMID:15269929

6. WHO warns of increased risk of disease epidemics in Syria and in neighbouring countries as summer approaches. Cairo: World Health Organization Regional Office for Eastern Mediterranean; 2013 (http://www.emro.who.int/press-releases/2013/disease-epidemics-syria.html, accessed 3 March 2018).

7. Members of the WHO programme for international drug monitoring. Uppsala: Uppsala Monitoring Centre; 2015 (https://www. who-umc.org/global-pharmacovigilance/members/who-programme-members/, accessed 10 May 2018).

8. [Adverse drug reaction reporting]. Damascus: Ministry of Health; 2015 (http://www.moh.gov.sy/Default.aspx?tabid=217, accessed 3 March 2018) (in Arabic).

9. Syrian Arab Republic pharmaceutical country profile. Damascus: Ministry of Health; 2011 (http://www.who.int/medicines/areas/ coordination/Syrian_Arab_Republic_PSCPNarrativeQuestionnaire_05122011.pdf, accessed 3 March 2018).

10. Wilbur K. Pharmacovigilance in the Middle East: a survey of 13 Arabic-speaking countries. Drug Saf. 2013 Jan;36(1):25-30. PMID:23315293

11. Suyagh M, Farah D, Abu Farha R. Pharmacist's knowledge, practice and attitudes toward pharmacovigilance and adverse drug reactions reporting process. Saudi Pharm J. 2015 Apr;23(2):147-53. PMID:25972734 http://dx.doi.org/10.1016/j.jsps.2014.07.001

12. Toklu HZ, Uysal MK. The knowledge and attitude of the Turkish community pharmacists toward pharmacovigilance in the Kadikoy District of Istanbul. Pharm World Sci. 2008;30:556-2. PMID:18350373

13. [List of Registered Pharmacists]. Damascus: Syrian Syndicate for Pharmacists; 2014 [in Arabic].

14. Herdeiro MT, Figueiras A, Polónia J, Gestal-Otero JJ. Influence of pharmacists' attitudes on adverse drug reaction reporting: a case-control study in Portugal. Drug Saf. 2006;29(4):331-40. PMID:16569082

15. Jose J, Jimmy B, Al-Ghailani AS, Al Majali MA. A cross sectional pilot study on assessing the knowledge, attitude and behaviour of community pharmacists to adverse drug reaction related aspects in the Sultanate of Oman. Saudi Pharm J. 2014 Apr;22(2):163-9. PMID:24648829

16. Gonzalez-Gonzalez C, Lopez-Gonzalez E, Herdeiro MT, Figueiras A. Strategies to improve adverse drug reaction reporting: a critical and systematic review. Drug Saf. 2013;36(5):317-28. PMID:23640659 
17. Arah, E. Community pharmacists' medication knowledge: a nation-wide study in Palestine [thesis]. Nablus: Najah University; 2012. (http://scholar.najah.edu/sites/default/files/Enass\%20Abu\%20Arah.pdf, accessed 3 March 2018).

18. Bawazir SA. Attitude of community pharmacists in Saudi Arabia towards adverse drug reaction reporting. Saudi Pharm J. 2006;14(1):75-83.

19. Angley M, Rigby D, Dowling HV, Coombes I, Criddle D, Dooley M, et al. Advocating for patients and the pharmacist's role in primary care. J Pharm Pract. 2014;44(1):6-9. DOI: 10.1002/j.2055-2335.2014.tboooo4.X 